ventilation at the time of re-LTx. Although our patient had severe respiratory compromise, he had preserved muscle mass, was several years removed from his most recent transplant, and had no other organ system failure such as renal dysfunction.

BOS remains the main cause of chronic graft dysfunction after LTx, and retransplantation is the only definitive treatment. ${ }^{6}$ Freedom from BOS in patients with $\mathrm{CF}$ receiving LTx is disappointingly low, only $38 \%$ at 10 years. ${ }^{7}$ Because of their young age at initial transplantation, an increasing number of patients with CF may eventually require re-LTx and perhaps even multiple transplants. ${ }^{8}$ This case report is the first to describe third-time LTx in this patient population.

Our initial concern when considering this patient for third-time surgery was that pleural adhesions that often accompany suppurative lung disease might prove problematic in the reoperative setting. Although pleural adhesions were noted to be significant and likely contributed to the complication of postoperative hemothorax, they were not prohibitive. An additional concern was that the patient might have early BOS given his shortened BOS-free survival after the second LTx when compared with the first. However, at 24 months since his transplant, the patient has had no evidence of acute or chronic rejection. In the only other report of a patient undergoing third-time LTx, in Australia, a Maastricht category IV donor after cardiac death was used because of ethical concerns about appropriate organ allocation. ${ }^{5}$ The authors suggest that this "extended criteria" donor otherwise would not have been used. The lung allocation score and system of organ allocation preclude such an approach in the United States, and the ethical debate regarding organ allocation for retransplantation remains unresolved.

\section{CONCLUSIONS}

Clearly, this is a single patient outcome, and this report should not be considered an endorsement of broad adoption of third-time LTx. However, this case demonstrates the feasibility and good mid-term survival of a third-time LTx with no obvious early immune-mediated dysfunction. Larger series of third-time transplant recipients will be necessary to determine the appropriateness of this aggressive therapy.

\section{References}

1. Novick RJ, Stitt LW, Al-Kattan K, et al. Pulmonary retransplantation: predictors of graft function and survival in 230 patients. Pulmonary Retransplant Registry. Ann Thorac Surg. 1998;65:227-34.

2. Brugiere $\mathrm{O}$, Thabut $\mathrm{G}$, Castier Y, et al. Lung retransplantation for bronchiolitis obliterans syndrome: long-term follow-up in a series of 15 recipients. Chest. 2003; 123:1832-7.

3. Strueber M, Fischer S, Gottlieb J, et al. Long-term outcome after pulmonary retransplantation. J Thorac Cardiovasc Surg. 2006;132:407-12.

4. Kawut SM, Lederer DJ, Keshavjee S, et al. Outcomes after lung retransplantation in the modern era. Am J Respir Crit Care Med. 2008;177:114-20.

5. Oto T, Rowland M, Griffiths AP, et al. Third-time lung transplant using extended criteria lungs. Ann Thorac Surg. 2007;84:642-4.

6. Kotloff RM. Lung retransplantation: all for one or one for all? Chest. 2003;123 1781-2.

7. Meachery G, De Soyza A, Nicholson A, et al. Outcomes of lung transplantation for cystic fibrosis in a large UK cohort. Thorax. 2008;63:725-31.

8. Morton J, Glanville AR. Lung transplantation in patients with cystic fibrosis Semin Respir Crit Care Med. 2009;30:559-68.

\title{
Acute limb ischemia after internal thoracic artery harvesting: A case report
}

\author{
Linda M. de Heer, MD, Marc P. Buijsrogge, MD, and Jaap R. Lahpor, MD, Utrecht, The Netherlands
}

The use of the left internal thoracic artery and/or right internal thoracic artery for coronary revascularization is preferable to ensure prolonged graft patency. ${ }^{1}$ We report the case of a 69 -year-old man who underwent coronary artery bypass

\footnotetext{
From the Department of Cardio-Thoracic Surgery, Division of Heart and Lungs, University Medical Center, Utrecht, The Netherlands.

Disclosures: Authors have nothing to disclose with regard to commercial support.

Received for publication May 25, 2010; revisions received July 2, 2010; accepted for publication Sept 10, 2010; available ahead of print Oct 29, 2010.

Address for reprints: Linda M. de Heer, MD, Department of Cardio-Thoracic Surgery, University Medical Center Utrecht, PO Box 85500, 3508 GA Utrecht, The Nether-

lands (E-mail: L.M.deheer-2@umcutrecht.nl).

J Thorac Cardiovasc Surg 2011;141:e5-7

$0022-5223 / \$ 36.00$

Copyright (c) 2011 by The American Association for Thoracic Surgery

doi:10.1016/j.jtcvs.2010.09.030
}

grafting in which harvesting of the left internal thoracic artery resulted in critical ischemia of the left limb, leaving upper leg amputation as the only option. This patient had a long-standing occlusion of the distal abdominal aorta and the left and right common iliac arteries with an open external iliac and left common femoral artery and completely relied on the internal thoracic arteries as the major source of blood supply to the legs. A recommendation for the management of patients with indications for coronary artery bypass grafting and aorto-iliac occlusive disease is given.

\section{CLINICAL SUMMARY}

A 69-year-old man was admitted to the hospital because of chronic stable angina pectoris. On physical examination, 
pulsations of both the femoral and distal arteries were absent. Coronary angiographic analysis, performed through the left radial artery, demonstrated 2-vessel disease (left anterior descending artery and left circumflex artery). To evaluate the peripheral circulation, 64-slice computed tomographic (CT) analysis (Philips Medical Systems, Best, The Netherlands) was performed and showed a complete occlusion of both the distal abdominal aorta and the left and right common iliac arteries. The common femoral arteries were both filled by collateral arteries. In addition, the superficial femoral arteries were both occluded, leaving both lower legs perfused by the deep femoral arteries.

The patient underwent coronary artery bypass grafting $(\mathrm{CABG})$ with the left internal thoracic artery (ITA), which was anastomosed to the left anterior descending artery. The saphenous vein was anastomosed to the first and second obtuse marginal arteries.

About 36 hours after the operation, the patient presented with unbearable pain, coldness, and numbness of his left lower leg. The patient displayed a pale leg, which was cold from the upper thigh downward, in addition to delayed capillary and venous filling. Exploration of the groin by the vascular surgeon showed chronic occlusion of the left superficial femoral artery, in accordance with the CT scan, without signs of acute thromboembolic phenomena. The attempt to perform a fasciotomy failed because of necrotic muscles of the left lower leg, leaving upper leg amputation as the only option.

In retrospect, analysis of the CT results with 3-dimensional reconstruction showed a collateral arterial pathway from the left ITA to the external iliac artery and the left common femoral artery as the major source of blood supply to the lower limb.

\section{DISCUSSION}

Most patients with aortoiliac occlusive disease (occlusion of the distal aorta, the common iliac artery, or both) do not have ischemia severe enough to cause rest pain. Lower limb viability in this setting is completely dependent on adequate thoracoabdominal collateral circulation. Various collateral pathways that can reconstitute the arteries of the pelvis and lower extremities have been described..$^{2-4}$ In general, there are 2 principal pathways: the visceral collateral and parietal collateral pathways. The arteries that commonly contribute to the visceral collateral pathways are the superior and inferior mesenteric artery and branches of the hypogastric artery. The parietal collateral pathway involves the subclavian artery, the ITA, the superior epigastric artery (SEA), and the inferior epigastric artery (IEA), forming ipsilateral collaterals to the limb through the external iliac artery and the common femoral artery.

In patients with aortoiliac occlusive disease, the relative contribution of each of these collateral pathways in preserv- ing limb perfusion is unknown; however, the ITA-SEA-IEA pathway (Winslow pathway) is the most important collateral pathway to the lower extremities in case of an open external iliac artery and common femoral artery, although the exact prevalence is unknown. ${ }^{5}$

The use of the left ITA, right ITA, or both for coronary revascularization has become the most common graft choice in CABG because of better graft patency and long-term survival compared with venous grafts. ${ }^{1}$ However, in patients with aortoiliac occlusive disease including an open external iliac artery and common femoral artery, the ITA functions as a potential major collateral artery. Not being aware of this possible circulatory pathway can lead to serious complications, as demonstrated in this case report.

Patients with aortoiliac occlusive disease who undergo CABG should be subjected to further investigation to delineate the diseased status of the peripheral circulation. The flow chart depicted in Figure 1 might aid surgeons in deciding on the right course of action for this group of patients. In patients with aortoiliac occlusion and an open external iliac artery and common femoral artery, we recommend to avoid use of the ipsilateral ITA. Alternatives are harvesting of the contralateral ITA or the radial artery, venous grafting, lower limb revascularization before CABG, or percutaneous coronary intervention. A large caliber of the ITA during the harvesting phase of a CABG procedure should raise suspicion that it

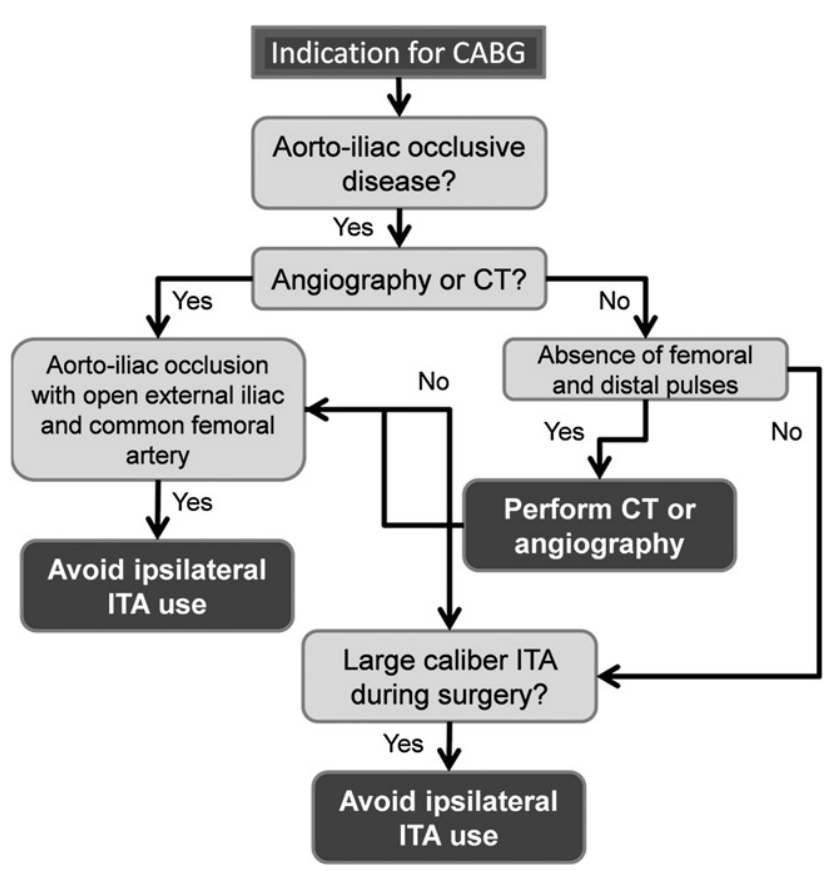

FIGURE 1. Flow chart showing recommendation for patients with indications for coronary artery bypass grafting with peripheral artery disease. $C A B G$, Coronary artery bypass grafting; $C T$, computed tomography; ITA, internal thoracic artery. 
potentially represents an important collateral pathway, and we would therefore recommend its preservation.

This case report underlines the importance of being aware of collateral circulation in patients with aortoiliac occlusive disease undergoing coronary bypass surgery. Harvesting the ITA can cause acute limb ischemia in this subset of patients. Awareness of the potential collateral ITA-SEA-IEA pathway and the possible complications after ITA harvesting could avoid acute limb ischemia.

\section{References}

1. Barner HB, Standeven JW, Reese J. Twelve-year experience with internal mammary artery for coronary artery bypass. J Thorac Cardiovasc Surg. 1985;90:668-75.

2. LeRiche R. De la resection du Carrefour aortico-l'iliaque avec double sympathectomie lombaire pour thrombose arteritique de l'aorte: le syndrome de l'obliteration termino-aortique pour arterite. Presse Med. 1940;48:601-15.

3. Edwards EA, Lamay M. Occlusion patterns and collaterals in arteriosclerosis of the lower aorta and iliac arteries. Surgery. 1955;38:950-63.

4. Grollman JH. Winslow's pathway-it is not the only way. Catheter Cardiovasc Interv. 2000;49:445-6

5. Tsui SSL, Parry AJ, Large SR. Leg ischemia following bilateral internal thoracic artery and inferior epigastric artery harvesting. Eur J Cardiothorac Surg. 1995;9: 218-20.

\title{
Giant bronchogenic cyst within the aortic wall mimicking symptoms of acute type A aortic dissection
}

\author{
Ömer Senbaklavaci, MD, ${ }^{\mathrm{a}}$ Lars Oliver Conzelmann, MD, ${ }^{\mathrm{a}}$ Christoph Brochhausen, MD, ${ }^{\mathrm{b}}$ and
} Christian F. Vahl, MD, ${ }^{\mathrm{a}}$ Mainz, Germany

Bronchogenic cysts are the most common cystic lesions of the mediastinum. We report a patient who presented with chest pain and an aortic enlargement that was misdiagnosed as an acute type A dissection. Intraoperatively, this was

From the Department of Cardiothoracic and Vascular Surgery ${ }^{\mathrm{a}}$ and the Institute of Pathology, ${ }^{\mathrm{b}}$ University Medical Center of the Johannes Gutenberg-University, Mainz, Germany.

Disclosures: Authors have nothing to disclose with regard to commercial support.

Received for publication May 26, 2010; revisions received Sept 4, 2010; accepted for publication Sept 17, 2010; available ahead of print Nov 8, 2010

Address for reprints: Ömer Senbaklavaci, MD, Department of Cardiothoracic and Vascular Surgery, University Medical Center of the Johannes Gutenberg-University, Langenbeckstr. 1, 55131 Mainz, Germany (E-mail: senbak@hotmail.com).

J Thorac Cardiovasc Surg 2011;141:e7-8

$0022-5223 / \$ 36.00$

Copyright (c) 2011 by The American Association for Thoracic Surgery

doi:10.1016/j.jtcvs.2010.09.031 identified as a cystic lesion originating within the aortic wall. To our knowledge, this is the first reported case of a bronchogenic cyst within the aortic wall causing acute symptoms of an acute type A aortic dissection.

\section{CLINICAL SUMMARY}

A 35-year-old man was referred to our department for emergency operation after onset of acute chest pain and dyspnea. A computed tomographic scan (Figure 1) showed a $7.5 \times 7.5 \times 5.5-\mathrm{cm}$ ascending aorta with a $1-\mathrm{cm}$ pericardial effusion retrocardially accompanied by an echocardiogram demonstrating a grade II to III aortic regurgitation. In consideration of these findings and the acute symptoms of the patient, an intramural hematoma with a beginning type A dissection of the ascending aorta could not be excluded definitively.

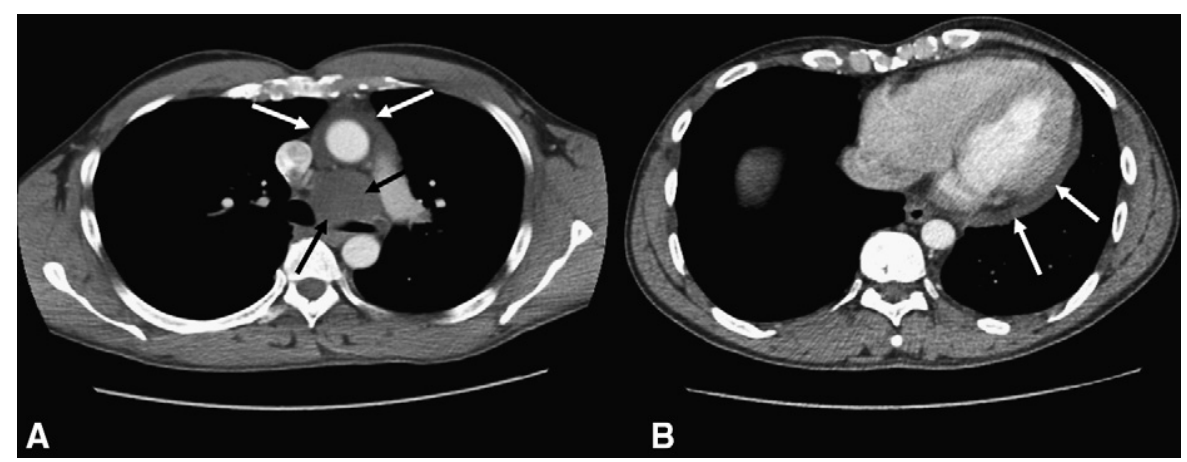

FIGURE 1. Computed tomographic images. A, White arrows show a thickening of the ascending aortic wall, a finding suggestive of intramural hematoma. Black arrows show a $7.5 \times 7.5 \times 5.5-\mathrm{cm}$ fluid lesion behind the ascending aorta with compression of the left main bronchus. B, Arrows show a 1 -cm pericardial effusion retrocardially. 